\title{
VARIABILIDADE TERMAL DE ÁREAS VERDES PÚBLICAS NA CIDADE DE GARANHUNS-PE
}

\author{
Ana Maria Severo Chaves ${ }^{(a)}$, Felippe Pessoa de Melo ${ }^{(b)}$, Rosemeri Melo e Souza ${ }^{(\mathrm{c})}$ \\ (a) Programa de Pós-Graduação em Geografia/Universidade Federal de Sergipe, anamschaves05@gmail.com \\ ${ }^{(b)}$ Colegiado de Geografia /UniAGES, felippemelo@hotmail.com \\ (c) Programa de Pós-Graduação em Geografia / Departamento de Engenharia Ambiental / UFS, rome@ufs.br
}

\section{Eixo: Climatologia em Diferentes Níveis escalares: mudanças e variabilidades}

\begin{abstract}
Resumo
A pesquisa teve por objetivo realizar uma análise espaço-temporal da temperatura da superfície (TS) do sítio urbano da cidade de Garanhuns-PE com destaque para áreas verdes públicas. A partir de Sistema de Informações Geográficas (SIGs) foi possível realizar os mapeamentos pretendidos para a banda termal do satélite landsat 5. Como procedimentos técnicos foram utilizados os softwares Idrisi na conversão dos níveis de cinza do raster em temperatura e o ArcGIS para análise e classificação dos dados. Como resultados constatou-se que devido ao tamanho das áreas verdes, que são menores que os pixels do raster, a temperatura superficial dessas áreas não difere do entorno, no entanto o calor verificado nos locais das áreas verdes não atinge a temperatura máxima averiguada no sítio urbano. Conclui-se que pesquisas como essas tendem a aumentar graças às possibilidades geradas pelo geoprocessamento e sensoriamento remeto por permitirem obter informações relevantes para o planejamento urbano.
\end{abstract}

Palavras-chave: Temperatura da Superfície. Sítio Urbano. Sistema de Informações Geográficas (SIG).

\section{Introdução}

A variação térmica na cidade é algo perceptível nos diferentes espaços urbanos. No caso de uma determinada pessoa que estiver caminhando por uma avenida arborizada durante o período da manhã e posteriormente passar por uma calçada sem vegetação, consequentemente sentirá a variação da temperatura em seu corpo facilmente. Essa sensação térmica é proporcionada pela radiação solar, que varia no espaço e tempo.

Enquanto elemento climático, a radiação solar se apresenta como uma variável que permite quantificar a energia proveniente do sol que é absorvida e refletida pela superfície da Terra. Ao mesmo tempo a radiação solar é um fator do clima, pois condiciona a temperatura do ar e a pressão atmosférica (STEINKE, 2012).

Para a realização de pesquisa sobre o clima urbano, a cidade tem que ser entendida como um ambiente aberto à troca de mateira e energia susceptível as intervenções antrópicas em diferentes escalas e usos do 
XVII Simpósio Brasileiro

de Geografia Fisica Aplicada

I Congresso Nacional de Geografia Física
OS DESAFIOS DA GEOGRAFIA FÍSICA NA FRONTEIRA DO CONHECIMENTO

Instituto de Geociências - Unicamp

Campinas - SP

28 de Junho à 02 de Julho de 2017

solo urbano. De acordo com Mendonça (2015), a maior parte dos estudos do clima urbano no Brasil tem levado em consideração a variação hipsométrica e o uso do solo.

As cidades, por sua vez, atuam como fatores modificadores do clima regional, criando condições específicas na atmosfera, que é definido como clima urbano. Os principais elementos responsáveis pela especificidade do clima nas cidades são: as construções, os tipos de materiais utilizados nas construções, os traçados das ruas, a circulação de veículos, as indústrias e as atividades humanas (AMORIM, 2013).

Nesse contexto urbano, os parques, praças, canteiros centrais, calçadas arborizadas e áreas verdes no geral representam indicadores que permitem sentir como a temperatura varia na malha urbana criando um microclima local. Pois, a temperatura nas cidades associada a falta de circulação de ar reflete na formação de ilhas de calor, esse fato denúncia à ausência de vegetação e maior adensamento estabelecido por grandes edifícios.

As ilhas de calor estão associadas a cobertura e usos da terra constituída nas áreas densamente urbanizadas e industrializadas, por sua vez, o efeito oásis é decorrente do frescor de áreas verdes ou corpos d'água (COELHO, 2013). As temperaturas mais amenas registradas nas cidades correspondem as áreas de vegetação densa (SOUZA; FERREIRA, 2012).

A ilha de calor pode ser responsável pelo mal-estar causado a população, diminuído a qualidade ambiental local, bem como, a qualidade de vida das pessoas que habitam ou trabalham nesse ambiente quente com pouca ventilação.

As áreas verdes públicas (AVPs) são essenciais para um ambiente citadino equilibrado e para o desenvolvimento de atividades urbanas diversas. A presença vegetal além de absorver parte da poluição emitida pelos meios de transportes e indústrias, essa representa um atenuante na diminuição das altas temperaturas e de ruídos que causam estresse e/ou incômodo.

De acordo com o Ministério do Meio Ambiente (MMA, 2014) as áreas verdes urbanas representam um conjunto de áreas intraurbanas que apresentam cobertura vegetal arbórea, arbustiva ou rasteira (nativa e/ou introduzida) que contribuem de modo significativo para a qualidade de vida e o equilíbrio ambiental das cidades. Essas estão presentes em áreas públicas ou particulares, como: áreas de preservação permanente, jardins, praças, parques, em terrenos e outros espaços livres.

Diante de tal contexto, atualmente as técnicas do geoprocessamento e do sensoriamento remoto permitem o desenvolvimento de pesquisas capazes de verificar a variação termal das cidades em diferentes recortes temporais, o que possibilitar uma análise da variação termal do sítio urbano bem como de elementos específicos como as áreas verdes. 


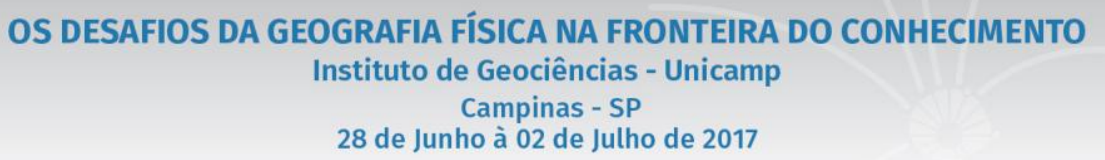

Para Coelho (2013) as técnicas do sensoriamento remoto, infravermelho termal, se apresentam como uma possibilidade para investigar o clima urbano, pois permite detectar as características térmicas dos diferentes elementos que compõem a superfície urbana.

Assim, a presente pesquisa teve por objetivo realizar uma análise espaço-temporal da temperatura da superfície (TS) do sítio urbano da cidade de Garanhuns-PE, destacando a variabilidade termal das áreas verdes públicas.

\section{A Cidade de Garanhuns-PE}

Garanhuns está localizado na Microrregião de Garanhuns no Estado de Pernambuco, a 228,8 Km da capital Recife, nas coordenadas geográficas de $08^{\circ} 53^{\prime} 25^{\prime \prime}$ de latitude sul e $36^{\circ} 29^{\prime} 34^{\prime \prime}$ de longitude oeste. Faz limite ao norte com Capoeira e Jucati, a sul com Terezinha, Lagoa do Ouro, Brejão e Correntes, a leste com São João e Palmeirina, e a oeste com Caetés, Saloá, Paranatama, Brejão e Terezinha (MASCARENHAS et al., 2005) (Figura 1).

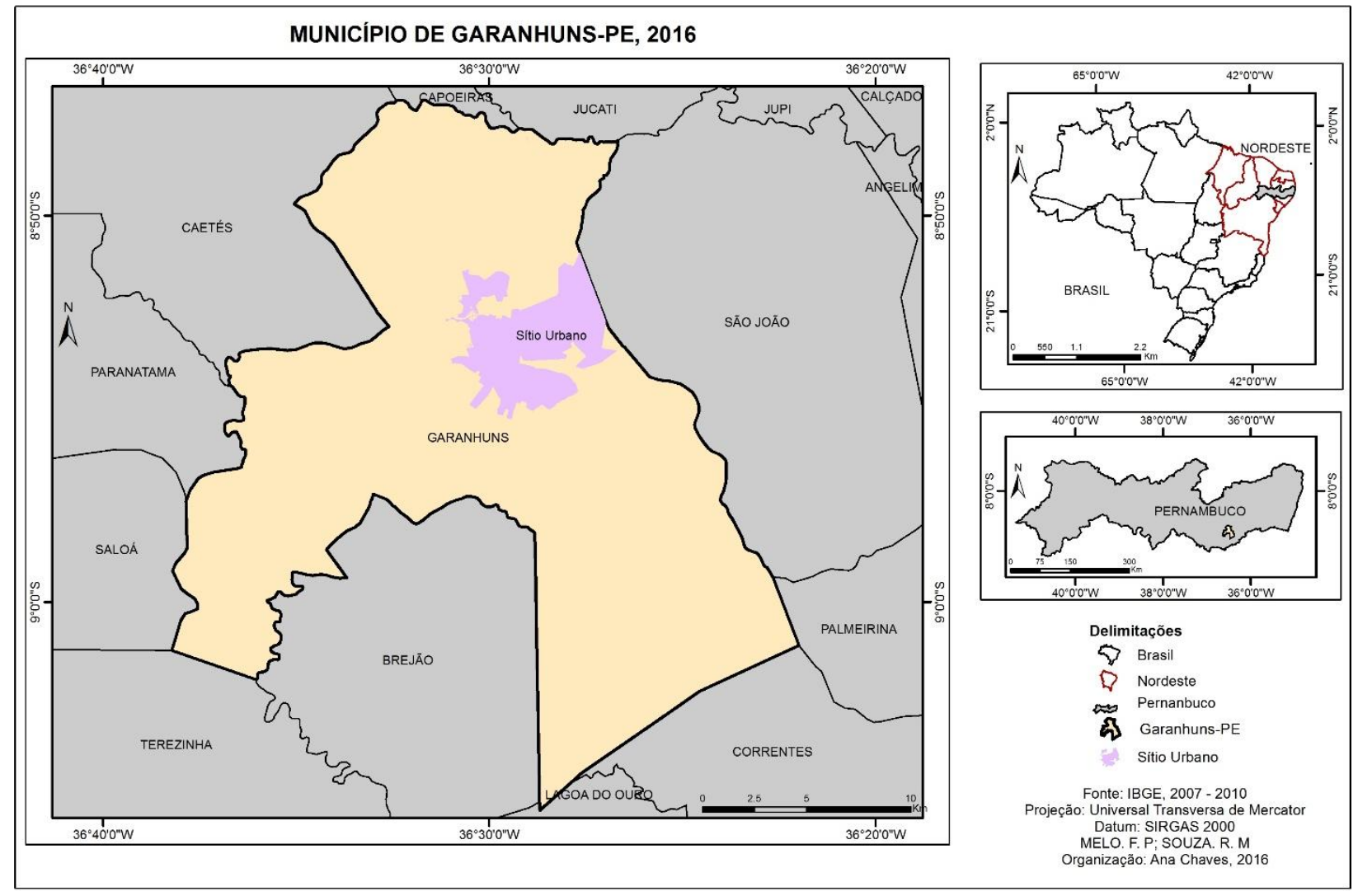

Figura 1 - Mapa de localização do município de Garanhuns-PE. 
XVII Simpósio Brasileiro

de Geografia Fisica Aplicada

I Congresso Nacional

de Geografia Física
OS DESAFIOS DA GEOGRAFIA FÍSICA NA FRONTEIRA DO CONHECIMENTO

Instituto de Geociências - Unicamp

Campinas - SP

28 de Junho à 02 de Julho de 2017

A população absoluta é de 129.408 habitantes, desses 115.356 residem no sítio urbano (IBGE, 2010). A região de Garanhuns é conhecida como bacia leiteira do Estado, destacando-se na produção artesanal, semi-artesanal e industrial de laticínios. Também é desenvolvida na região a cultura de subsistência com plantios de feijão, milho e mandioca e em área de brejo encontra-se cultura permanente de café e a fruticultura (SILVA FILHO et al, 2007).

A composição geológica faz parte do Complexo Cabrobó, o qual é formado por associação de várias rochas. O solo encontrado é do tipo Latossolos Amarelos e Gleissolos de Várzea. O munícipio apresenta uma altitude média de $842 \mathrm{~m}$. O relevo faz parte das unidades de superfícies retrabalhadas por ação hídrica, dissecado nos topos dos morros com vales profundos, contemplando uma paisagem de mares de morros com feições tabulares, localizada no Planalto da Borborema (GUIMARÃES, 2005).

O clima de Garanhuns é do tipo mata de altitude, mesotérmico úmido, caracteriza-se por temperatura média anual de 20 graus, com mínimas durante agosto de $8^{\circ} \mathrm{C}$ e máxima de $30^{\circ} \mathrm{C}$ nos meses de novembro e dezembro, com precipitação média anual é de 908,6 mm, inserido na bacia do rio mundaú, numa zona de transição composta por duas regiões fitogeográfica, mata de altitude e agreste, correspondendo a transição entre mata e caatinga (SILVA FILHO et al, 2007).

O presente texto faz parte de uma pesquisa maior, a qual se dedicou a analisar os indicadores ambientais das principais áreas verdes públicas da cidade de Garanhuns-PE. Essas correspondem a 15 áreas estudadas ( 2 parques urbanos, 4 canteiros centrais e 9 praças), que estão localizadas em apenas quatro dos doze bairros que compõem o sítio urbano da cidade, são: Boa Vista, Magano, Heliópolis e Santo Antônio.

\section{Procedimentos metodológicos}

A presente pesquisa realizou o mapeamento da temperatura da superfície (TS) do sítio urbano de Garanhuns em espaço-temporal de 1991, 2001 e 2010, com a intenção de verificar a variação termal das áreas verdes públicas correspondendo as bandas termais obtidas na época da primavera em 14 de dezembro de 1991, 22 de outubro de 2001 e 29 de setembro de 2010.

Para a realização do mapeamento foi necessário buscar suporte no geoprocessamento e sensoriamento remoto (RS) com subsídio dos softwares Idrisi e ArcGIS. Com a utilização de imagens do satélite landsat

5 do sensor TM, especificamente a banda termal disponível gratuitamente pelo Instituto Nacional de Pesquisas Espaciais (INPE), para obter as informações necessárias para a presente análise. 
XVII Simpósio Brasileiro

de Geografia Fisica Aplicada

I Congresso Nacional

de Geografia Física
OS DESAFIOS DA GEOGRAFIA FÍSICA NA FRONTEIRA DO CONHECIMENTO

Instituto de Geociências - Unicamp

Campinas - SP

28 de Junho à 02 de Julho de 2017

\subsection{Mapeamento da temperatura da superfície}

A obtenção da temperatura da superfície deu-se por meio de imagem do satélite LANDSAT 5 TM, especificamente a banda 6 termal disponível no INPE (disponíveis em: http://www.dgi.inpe.br/CDSR/). Utilizando os seguintes softwares e procedimentos na preparação do mapa:

$\checkmark$ Idrisi 17.0: converteu os níveis de cinza da imagem em temperatura $\left(\mathrm{C}^{\circ}\right)$ através da ferramenta THERMAL, por seguinte foi escolhido a quantidade de classes desejadas e salva no formato GEOTIFF;

$\checkmark$ ArcGIS 10.2.1: projetada a banda termal para UTM, Zona -24, Datum SIRGAS 2000 . O georreferenciamento das bandas termal se deu a partir de pontos de controle e de uma imagem já georreferenciadas. A classificação se fez pela seleção do número de classes desejadas e cores correspondentes, adicionando uma imagem processada e colorida para analisar o que cada classe de temperatura $\left(\mathrm{C}^{\circ}\right)$ representa na superfície. Por fim, inserido o layout de acordo com as normas cartográficas utilizadas (MARTINELLI, 2013) e confeccionando o mapa de temperatura.

Após mapear a temperatura do sítio urbano nas datas mencionadas, verificou-se a temperatura absorvida pelas áreas verdes públicas colocando em destaque os valores da variação termal. Assim, a numeração de 1 a 15, presente nas figuras (mapas) 2, 3 e 4, corresponde à localização das áreas verdes pesquisadas no sítio urbano de Garanhuns.

\section{Resultados e discussões}

O trabalho realizado por França, Chaves e Pinto (2016) aponta que as menores temperaturas encontradas sobre o sítio urbano de Garanhuns localizam-se no entorno de nascentes urbanas e cursos d’águas, por haver a presença de vegetação.

O estudo de Melo (2016) demonstra que a formação de ilhas de calor no sítio urbano da cidade de Garanhuns se desenvolve, movimenta e intensifica com o passar dos anos à medida que o adensamento urbano aumenta. Essas ocorrem nas proximidades do principal centro comercial, o bairro Santo Antônio, localizado na porção de baixa altitude quando correlacionado aos demais bairros analisados.

A pesquisa do referido autor constatou que o comportamento térmico ocorrido em 2001 e 2010 segue a mesma tendência com "a intensificação dos processos de antropização das áreas e o aumento das médias termais" (MELO, 2016, p. 189). Conforme Melo (op cit.), em 2001 foi diagnosticada a presença de duas ilhas de calor sobre o sítio urbano, já em 2010 verificou características da presença de uma única, resultante da unificação das ilhas de calor anteriores. 
As áreas verdes públicas da cidade de Garanhuns apresentam um microclima ameno na malha urbana, pois são espaços bem arborizados. Assim, para representar a temperatura das áreas verdes públicas se elaborou uma tabela com a variação de temperatura verificada nas áreas verdes públicas estudadas a partir da temperatura obtida no sítio urbano de Garanhuns, para assim melhorar a visualização dos dados.

O primeiro mapeamento corresponde ao registro de 14 de dezembro 1991, final da primavera, época em que a temperatura da superfície é elevada, com ausência ou pouca precipitação e baixa umidade do ar. Diante do respectivo contexto, o mapa de temperatura da superfície (TS) do sítio urbano de Garanhuns demostra altas temperaturas, variando de $17^{\circ} \mathrm{C}$ a $36^{\circ} \mathrm{C}$, como visualizado no mapa (figura 2).

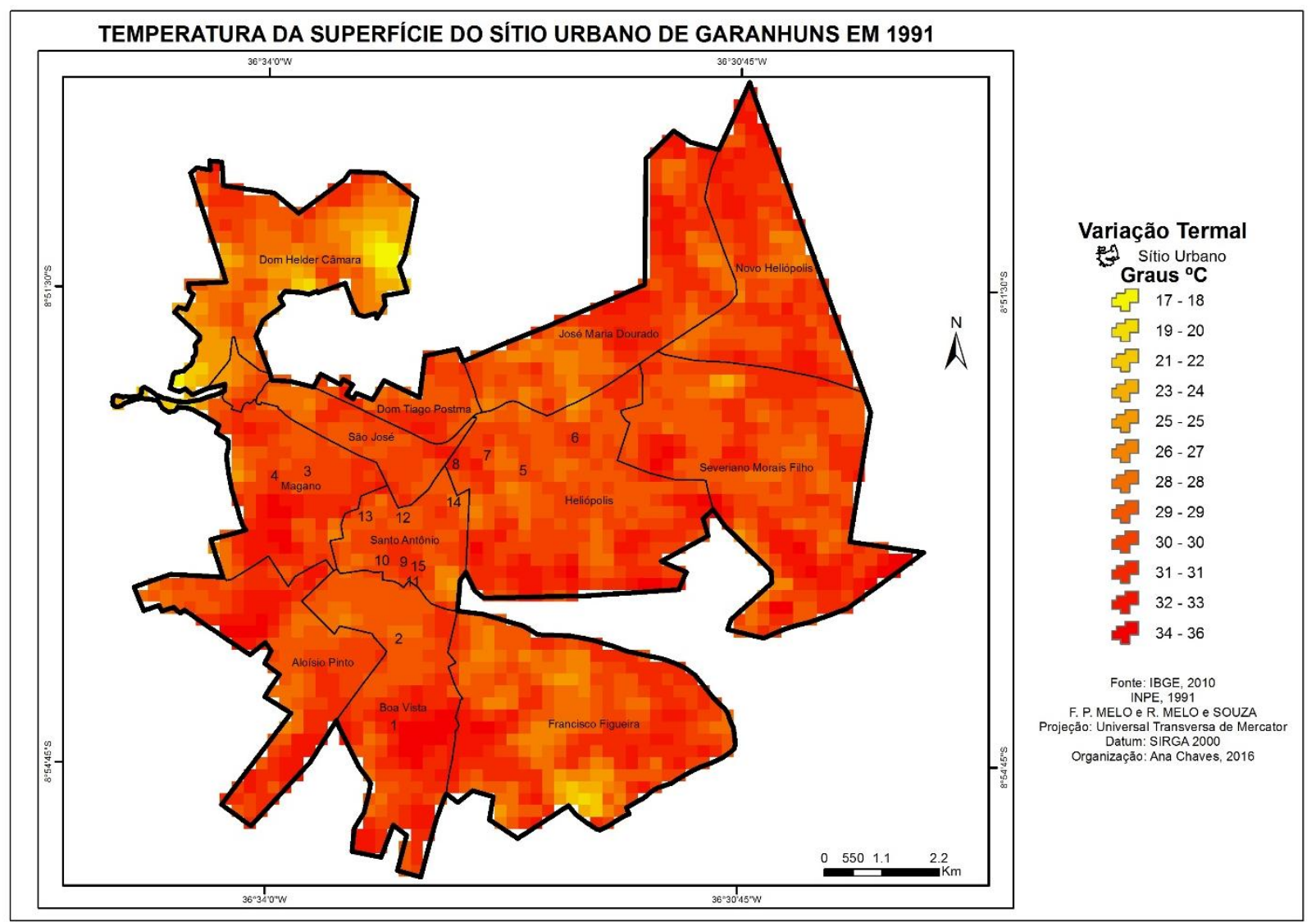

Figura 2 - Temperatura da superfície do sítio urbano de Garanhuns em 1991.

As temperaturas oscilam com uma variação de $20^{\circ} \mathrm{C}$, onde a mínima é de $17^{\circ} \mathrm{C}$ em extremidades do sítio urbano e a máxima de $36^{\circ} \mathrm{C}$ espalhadas nas áreas mais centrais dos bairros. Os bairros Santo Antônio e Heliópolis não possuem a temperatura máxima. Já o bairro Boa Vista e Magano apresentam em algumas partes as temperaturas máximas. 
XVII Simpósio Brasileiro de Geografia Fisica Aplicada

I Congresso Nacional de Geografia Física
OS DESAFIOS DA GEOGRAFIA FÍSICA NA FRONTEIRA DO CONHECIMENTO

Instituto de Geociências - Unicamp

Campinas - SP

28 de Junho à 02 de Julho de 2017

As TS referentes ao ano de 1991 foram as mais elevadas. Em contrapartida as temperaturas para o ano de 2001, correspondente a 22 de outubro, representam as mais baixas constatadas, com mínima de $16^{\circ} \mathrm{C}$ e a máxima de $27^{\circ} \mathrm{C}$, com uma variação de $12^{\circ} \mathrm{C}$ (figura 3 ).

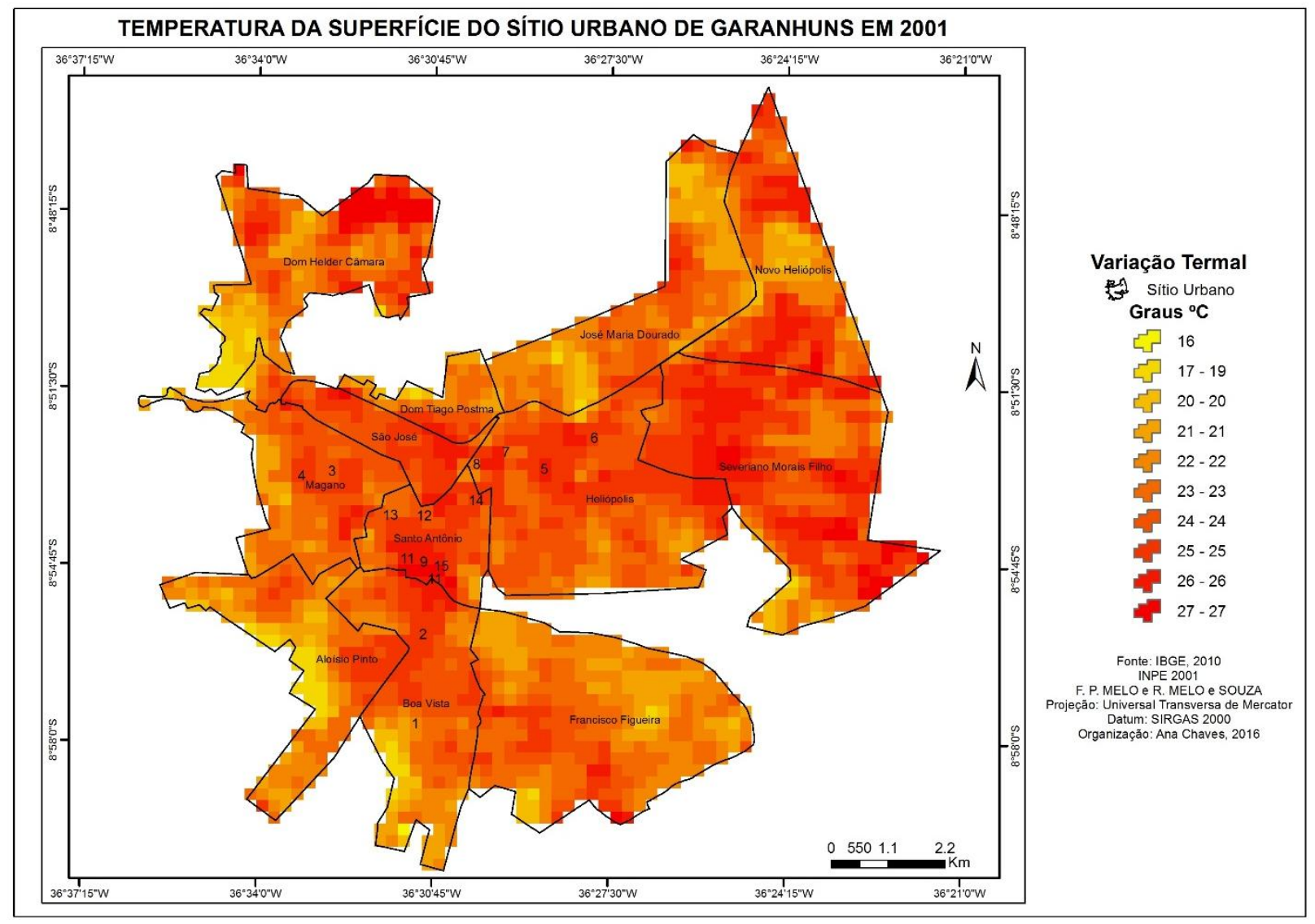

Figura 3 - Temperatura da superfície do sítio urbano de Garanhuns em 2001.

$\mathrm{Na}$ figura 3, se verificou que as temperaturas mais elevadas estão concentradas em partes centrais do sítio urbano. Isso destaca para formação de ilhas de calor na malha urbana de Garanhuns. Pois à medida que a urbanização se acentua, diminui a quantidade de solo permeável e aumenta o adensamento urbano, fatores esses capazes de dificultar a circulação do ar provocando o aumento da temperatura e inibição da circulação dos ventos.

Por fim, se fez a análise termal do raster correspondente ao dia 29 de setembro de 2010, período do início da primavera, no qual se verificou temperaturas intermediárias entre as máximas constatadas em 1991 e as mínimas verificadas no ano de 2001.

A variação termal para o ano de 2010 apresentou a mínima de $18^{\circ} \mathrm{C}$ e máxima de $30^{\circ} \mathrm{C}$, com a variabilidade de $13^{\circ} \mathrm{C}$ (figura 4 ). 


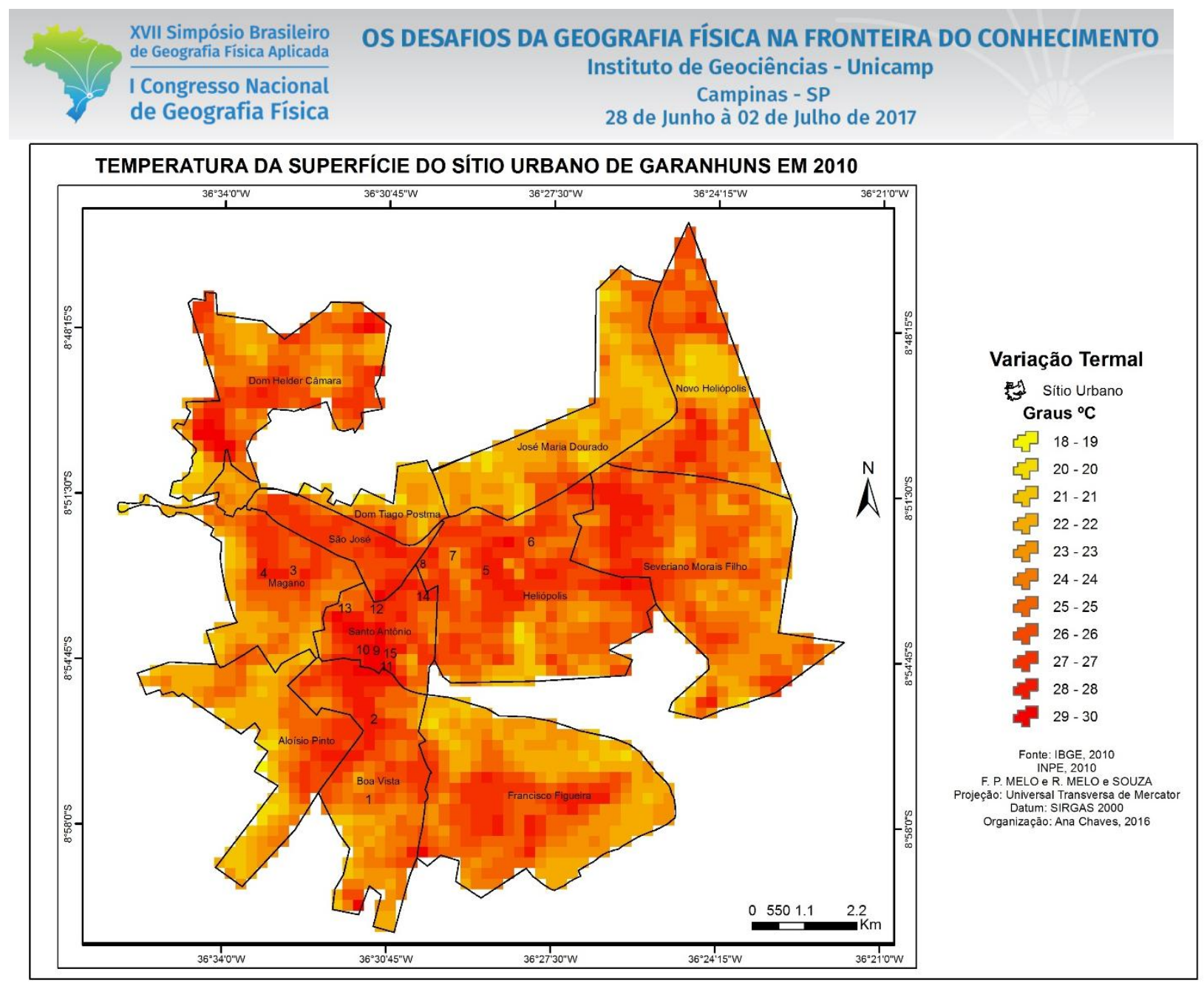

Figura 4 - Temperatura da superfície do sítio urbano de Garanhuns em 2010.

A partir dos dados históricos do Instituto Nacional de Meteorologia (INMET), foi possível obter informações sobre temperatura e pluviosidade na estação de Garanhuns (OMM: 82893) para os meses correspondentes a cada banda termal analisada. Mas por motivo desconhecido pela presente pesquisa, não foram encontrados dados referentes ao ano de 1991.

No ano de 2001, segundo os dados do INMET, o mês de outubro apresentou uma precipitação total de 123 mm e temperatura média máxima de $26,99^{\circ} \mathrm{C}$ e mínima de $17,61^{\circ} \mathrm{C}$. Informações condizentes com a TS obtida na banda termal.

Nas informações acerca do mês de setembro de 2010, se verificou uma precipitação total de 123, 6 mm e a temperatura média máxima $23,68{ }^{\circ} \mathrm{C}$. Isso aponta que a temperatura da superfície para o dia 29 de setembro, deste ano, esteve acima da média mensal.

Quanto à precipitação total, ambas se encontram acima da média, pois no mês de setembro as chuvas são escassas, fazendo refletir temperaturas mais amenas para o mês de outubro de 2001, o que permitiu obter TS baixas. 
Apesar da banda termal do landsat não possibilitar a obtenção da TS de todas as áreas verdes como pontos frios na malha urbana devido ao tamanho dos pixels da imagem, em quaisquer uns dos anos analisados não foi verificado a TS máxima identificada no sítio urbano para as AVPs.

A partir da variabilidade termal verificada no sítio urbano da cidade de Garanhuns elaborou-se uma tabela na qual é especificado a TS de cada área verde pública para os três anos estudados (Tabela I).

Tabela I - Variação termal das áreas verdes públicas de Garanhuns-PE.

\section{Variabilidade termal de áreas verdes públicas nos anos de 1991, 2001 e 2010}

\begin{tabular}{|c|c|c|c|c|c|c|c|}
\hline \multirow[t]{2}{*}{ Área verde } & & \multicolumn{2}{|r|}{1991} & \multicolumn{2}{|r|}{2001} & \multicolumn{2}{|r|}{2010} \\
\hline & $\mathrm{N}^{\circ}$ & Cor & Temperatura & Cor & Temperatura & Cor & Temperatura \\
\hline Praça Maceió & 1 & ᄃ & $28^{\circ} \mathrm{C}$ & 5 & $25^{\circ} \mathrm{C}$ & & $28^{\circ} \mathrm{C}$ \\
\hline $\begin{array}{c}\text { Praça Universitária } \\
\text { UFRPE }\end{array}$ & 2 & & $32{ }^{\circ} \mathrm{C}$ & & $22^{\circ} \mathrm{C}$ & & $25^{\circ} \mathrm{C}$ \\
\hline $\begin{array}{l}\text { Canteiro da Avenida } \\
\text { Santa Terezinha }\end{array}$ & 3 & & $29^{\circ} \mathrm{C}$ & & $24^{\circ} \mathrm{C}$ & & $26^{\circ} \mathrm{C}$ \\
\hline Praça Campus Sales & 4 & & $30^{\circ} \mathrm{C}$ & & $25^{\circ} \mathrm{C}$ & & $28^{\circ} \mathrm{C}$ \\
\hline $\begin{array}{c}\text { Canteiro da Avenida Rui } \\
\text { Barboza }\end{array}$ & 5 & & $30^{\circ} \mathrm{C}$ & & $24{ }^{\circ} \mathrm{C}$ & & $26^{\circ} \mathrm{C}$ \\
\hline Praça Tavares Correia & 6 & & $31^{\circ} \mathrm{C}$ & & $25^{\circ} \mathrm{C}$ & & $25^{\circ} \mathrm{C}$ \\
\hline Parque Euclides Dourado & 7 & & $30^{\circ} \mathrm{C}$ & & $24{ }^{\circ} \mathrm{C}$ & & $25^{\circ} \mathrm{C}$ \\
\hline $\begin{array}{c}\text { Canteiro da Avenida } \\
\text { Caruaru }\end{array}$ & 8 & & $30^{\circ} \mathrm{C}$ & & $23^{\circ} \mathrm{C}$ & & $26^{\circ} \mathrm{C}$ \\
\hline $\begin{array}{c}\text { Canteiro da Rua Severino } \\
\text { Peixoto }\end{array}$ & 9 & & $31^{\circ} \mathrm{C}$ & & $26^{\circ} \mathrm{C}$ & & $29^{\circ} \mathrm{C}$ \\
\hline Praça São Francisco & 10 & & $30^{\circ} \mathrm{C}$ & & $26^{\circ} \mathrm{C}$ & & $28^{\circ} \mathrm{C}$ \\
\hline Praça Dr. Aloísio Pinto & 11 & & $30^{\circ} \mathrm{C}$ & & $26^{\circ} \mathrm{C}$ & & $29^{\circ} \mathrm{C}$ \\
\hline Praça Dom Moura & 12 & & $29^{\circ} \mathrm{C}$ & & $24^{\circ} \mathrm{C}$ & & $27^{\circ} \mathrm{C}$ \\
\hline $\begin{array}{c}\text { Praça Monsenhor } \\
\text { Adelmar da Mota } \\
\text { Valença }\end{array}$ & 13 & & $29^{\circ} \mathrm{C}$ & & $23^{\circ} \mathrm{C}$ & & $24^{\circ} \mathrm{C}$ \\
\hline Praça Solto Filho & 14 & & $28^{\circ} \mathrm{C}$ & & $25^{\circ} \mathrm{C}$ & & $28^{\circ} \mathrm{C}$ \\
\hline $\begin{array}{c}\text { Parque Ruber Van Der } \\
\text { Linden }\end{array}$ & 15 & & $30^{\circ} \mathrm{C}$ & & $26^{\circ} \mathrm{C}$ & & $28^{\circ} \mathrm{C}$ \\
\hline
\end{tabular}


Para o ano de 1991 a TS das áreas verdes variam entre $28^{\circ} \mathrm{C}$ e $32^{\circ} \mathrm{C}$, com uma variabilidade termal de $5^{\circ} \mathrm{C}$ (tabela II). O calor máximo constatado foi na Praça Universitária UFRPE, localizada no bairro Boa Vista. Já a TS mínima de $28^{\circ} \mathrm{C}$ compreende a Praça Maceió (Boa Vista) e a Praça Solto Filho (Santo Antônio). As demais AVPs apresentaram uma variação termal entre $29^{\circ} \mathrm{C}$ a $31^{\circ} \mathrm{C}$.

Tabela II - Comparativo da variação termal entre o sítio urbano e as áreas verdes públicas de 1991.

Variabilidade termal entre o sítio urbano e as áreas verdes públicas, 1991

\begin{tabular}{c|c|c}
\hline Temperatura & Sítio urbano & Áreas verdes \\
\hline Mínima & $17^{\circ} \mathrm{C}$ & $28^{\circ} \mathrm{C}$ \\
\hline Máxima & $36^{\circ} \mathrm{C}$ & $32^{\circ} \mathrm{C}$ \\
\hline Variação termal & $20^{\circ} \mathrm{C}$ & $5^{\circ} \mathrm{C}$ \\
\hline
\end{tabular}

O ano de 2001 correspondeu às menores temperaturas verificadas na pesquisa. De acordo com a série histórica representou o mês com elevado índice pluviométrico. A temperatura mínima verificada foi de $22^{\circ} \mathrm{C}$ na Praça Universitária e a máxima de $26^{\circ} \mathrm{C}$ nas áreas verdes do bairro Santo Antônio presente no Parque Ruber Van Der Linden, nas Praças São Francisco e Dr. Aloísio Pinto e no Canteiro da Rua Severiano Peixoto. A variação termal entre as AVPs foi de $5^{\circ} \mathrm{C}$ (tabela III).

Tabela III - Comparativo da variação termal entre o sítio urbano e as áreas verdes públicas de 2001.

Variabilidade termal entre o sítio urbano e as áreas verdes públicas, 2001

\begin{tabular}{c|c|c}
\hline Temperatura & Sítio urbano & Áreas verdes \\
\hline Mínima & $16^{\circ} \mathrm{C}$ & $22^{\circ} \mathrm{C}$ \\
\hline Máxima & $27^{\circ} \mathrm{C}$ & $26^{\circ} \mathrm{C}$ \\
\hline Variação termal & $12^{\circ} \mathrm{C}$ & $5^{\circ} \mathrm{C}$ \\
\hline
\end{tabular}

As demais áreas verdes do bairro Santo Antônio exibem temperatura entre $23^{\circ} \mathrm{C}$ a $25^{\circ} \mathrm{C}$. Nos bairros Boa Vista e Magano, a TS foi de $24^{\circ} \mathrm{C}$ nas Praças Maceió e Campus Sales e de $25^{\circ} \mathrm{C}$ para o Canteiro Central da Av. Santa Terezinha. O bairro Heliópolis apresentou uma graduação crescente na temperatura, variando de $23^{\circ} \mathrm{C}$ no Canteiro Central da Av. Caruaru, $24^{\circ} \mathrm{C}$ para o Canteiro Central da Av. Rui Barboza e no Parque Euclides Dourado e de $25^{\circ} \mathrm{C}$ na Praça Tavares Correia.

Para o ano de 2010, a variabilidade termal foi de $6^{\circ} \mathrm{C}$, com mínima de $24^{\circ} \mathrm{C}$ na Praça Monsenhor Adelmar da Mota Valença e máxima de $29^{\circ} \mathrm{C}$ no Canteiro Central da Rua Severiano Peixoto e na Praça Dr. Aloísio 
Pinto (tabela IV). Ambas as temperaturas, mínima e máxima, são verificadas no bairro Santo Antônio, as demais áreas verdes desse bairro apresentaram variações entre $27^{\circ} \mathrm{C}$ e $28^{\circ} \mathrm{C}$.

Tabela IV - Comparativo da variação termal entre o sítio urbano e as áreas verdes públicas de 2010.

Variabilidade termal entre o sítio urbano e as áreas verdes públicas, 2010

\begin{tabular}{c|c|c}
\hline Temperatura & Sítio urbano & Áreas verdes \\
\hline Mínima & $18^{\circ} \mathrm{C}$ & $24^{\circ} \mathrm{C}$ \\
\hline Máxima & $30^{\circ} \mathrm{C}$ & $29^{\circ} \mathrm{C}$ \\
\hline Variação termal & $13^{\circ} \mathrm{C}$ & $6^{\circ} \mathrm{C}$ \\
\hline
\end{tabular}

O bairro Boa Vista teve $28^{\circ} \mathrm{C}$ na Praça Maceió, onde parte da superfície se encontra impermeável, e $25^{\circ} \mathrm{C}$ na Praça Universitária (UFRPE), cuja superfície é de solo permeável sem grama. No bairro Magano a TS das áreas verdes é de $26^{\circ} \mathrm{C}$ no Canteiro Central e $28^{\circ} \mathrm{C}$ na Praça. Já as áreas verdes do bairro Heliópolis apresentaram TS de $26^{\circ} \mathrm{C}$ nos canteiros centrais e $25^{\circ} \mathrm{C}$ na Praça e no Parque.

Por fim, verifica-se que a TS das áreas verdes públicas de 2001 é a menor verificada para os três anos; a Praça Maceió e a Praça Solto Filho apresentam a mesma temperatura em 1991 e 2010; a Praça Tavares Correia exibe a mesma TS para os anos de 2001 e 2010; os parques expõe temperatura de $30^{\circ} \mathrm{C}$ para o ano de 1991 , decrescendo no ano de 2001 para $24^{\circ} \mathrm{C}$ e $26^{\circ} \mathrm{C}$ e aumentando em 2010 para $25^{\circ} \mathrm{C}$ e $28^{\circ} \mathrm{C}$, tendo maior expressividade na variabilidade termal do parque Ruber Van Der Liden.

\section{Considerações finais}

A análise da variabilidade termal, em escala espaço-temporal, resultou em informações que permitem verificar mudanças ocorridas na paisagem a partir da temperatura absorvida pelos diversos elementos da superfície terrestre e as modificações sucedidas no decorrer da história.

Por meio do uso de ferramentas do geoprocessamento e sensoriamento remoto inúmeras pesquisas vêm sendo realizadas para a obtenção de informações que possam ser utilizadas para o planejamento urbano. Pois, dados como da temperatura da superfície evidencia como a temperatura de uma determinada área se comporta em diferentes escalas temporais e espaciais.

A partir dos dados alcançados nos mapas de variação termal para os anos de 1991, 2001 e 2010, é possível traçar um planejamento adequado no intuito de melhorar o conforto térmico da cidade de Garanhuns nas estações quentes, bem como, planejar estratégias que possam amenizar as ilhas de calor, que se vincularam com o passar dos anos, melhorando assim o microclima local. 
Aprimorar a qualidade das áreas verdes públicas, aumentar a quantidade de arborização em ruas e calçadas, são ações práticas que contribuem para melhorar as condições climáticas urbanas. E assim, esses espaços arborizados passarão a apresentar maior influência na temperatura da superfície das cidades.

\section{Bibliografia}

AMORIM, Margarete Cristiane de Costa trindade. Ritmo climático e planejamento urbano. In: AMORIM, Margarete Cristiane de costa Trindade; SANT' ANNA NETO, João Lima; MONTEIRO, Ana (Orgs). Climatologia urbana e regional: questões teóricas e estudos de casos. Outras Expressões: São Paulo, 2013.

COELHO, André Luiz Nascentes. Distribuição das Classes de Temperatura de Superfície a Partir da Faixa do Infravermelho Termal do Sensor TM/Landsat-5 no Município de Vitória (ES). Anais eletrônicos do XVI Simpósio Brasileiro de Sensoriamento Remoto - SBSR, 2013. p. 0826- 0833.

BRASIL, Instituto Nacional de Meteorologia-INMET. Banco de Dados Meteorológicos para Ensino e PesquisaBDMEP. Disponível em: <http://www.inmet.gov.br/portal/index.php?r=bdmep/bdmep>. Acesso em 14 julho de 2016.

FRANÇA, Elaynne Mirele Sabino de; CHAVES, Ana Maria Severo; PINTO, Josefa Eliane Santana de Siqueira. Susceptibilidades do clima de Garanhuns-Pernambuco, pelo índice de vegetação da diferença normalizada (NDVI) e pela temperatura superficial. Anais do XII Simpósio Brasileiro de Climatologia Geográfica, 2016, p. 661 - 672.

IBGE, Instituto Brasileiro de Geografia e Estatística. Censo 2010. Disponível em: <http://cidades.ibge.gov.br/xtras/home.php>. Acesso em: 25 de nov. de 2014.

INPE, Instituto Nacional de Pesquisas Espaciais. Catálogo de imagens. Disponível em: <http://www.dgi.inpe.br/siteDgi/portugues/index.php〉. Acesso em: 20 de abr. de 2015.

MARTINELLI, Marcello. Mapas da geografia e cartografia temática. 6. ed. São Paulo: Contexto, 2013.

MASCARENHAS, J. C.; BELTRÃO, B. A.; SOUZA JUNIOR, L. C.; GALVÃO, M. J. T. G.; PEREIRA, S. N.; MIRANDA, J. L. (Org.). Projeto cadastro de fontes de abastecimento por água subterrânea. Diagnóstico do município de Garanhuns, estado de Pernambuco. Recife: CPRM/PRODEEM, 2005.

MELO, Felippe Pessoa de. Risco ambiental e ordenamento do território em Garanhuns - PE. 2016. 248f. Tese (Doutorado em Geografia) - Universidade Federal de Sergipe, São Cristóvão, 2016.

MELO, Felippe Pessoa de; GOIS, Douglas Vieira; ARAÚJO, Wandson Silva; CHAVES, Ana Maria severo; MELO e SOUZA, Rosemeri. Estruturação de matriz de espacialização de dados geográficos em ambiente de SIGs. Anais do $4^{0}$ Simpósio sobre geotecnologias e geoinformação no Estado de Alagoas, 2016, p. 1-9.

MELO, F. P. de; MELO e SOUZA, R. Delimitação dos bairros da cidade de Garanhuns-PE em shapefiles. Garanhuns, 2015.

MENDONÇA, Francisco. O estudo do clima urbano no Brasil. In: MONTEIRO, Carlos Augusto de Figueiredo; MENDONÇA, Francisco. Clima Urbano. 2 ed. São Paulo: Contexto, 2015.

SILVA FILHO, A. F.; GOMES, H. A; Osako L. S.; GUIMARÃES, I. P.; BRASIL, E. A.; LIMA, D. R.; COCENTINO, L.; VILLAVERDE, V. G. R.; VASCONCELOS, C. L. Garanhuns - SC.24-X-B-VI, escala 1:100.000: nota explicativa. Pernambuco/Alagoas: UFPE /CPRM, 2007.

STEINKE, Ercília Torres. Climatologia fácil. São Paulo: Oficina de Textos, 2012. 


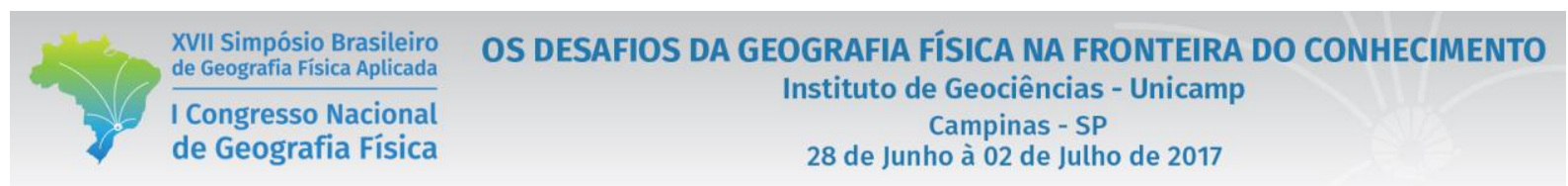

\section{Agradecimentos}

A primeira autora agradece ao Grupo de Pesquisa em Geoecologia e Planejamento Territorial GEOPLAN e ao CNPq pela concessão bolsa de estudo de Mestrado no Programa de Pós-Graduação em Geografia - PPGEO/UFS. 